\title{
Very Low Levels of Genetic Variation in Natural Peridomestic Populations of the Chagas Disease Vector Triatoma sordida (Hemiptera: Reduviidae) in Southeastern Brazil
}

\author{
Fernando A. Monteiro, * José Jurberg, and Cristiano Lazoski \\ Laboratório de Doenças Parasitárias, Instituto Oswaldo Cruz, Fiocruz, Rio de Janeiro, Brazil; Laboratório Nacional e Internacional de \\ Referência em Taxonomia de Triatomíneos, Instituto Oswaldo Cruz, Fiocruz, Rio de Janeiro, Brazil; Laboratório de Biodiversidade \\ Molecular, Departamento de Genética, Universidade Federal do Rio de Janeiro, Rio de Janeiro, Brazil
}

\begin{abstract}
Levels of genetic variation and population structure were determined for 181 Triatoma sordida insects from four populations of southeastern Brazil, through the analysis of 28 allozyme loci. None of these loci presented fixed differences between any pair of populations, and only two revealed polymorphism, accounting for low levels of heterozygosity $\left(H_{e}=0.027\right)$, and low genetic distances $(D<0.03)$ among populations. $F_{S T}$ and Contingency Table results indicated the existence of genetic structure among populations $\left(F_{S T}=0.214\right)$, which were incompatible with the isolation by distance model (Mantel test: $r=0.774 ; P=0.249)$.
\end{abstract}

\section{INTRODUCTION}

Triatoma sordida (Stål 1859) is the Chagas disease vector most frequently captured in the peridomestic environment in Brazil, particularly in areas where Triatoma infestans (Klug 1834) has been eliminated ${ }^{1,2}$ by the Southern Cone Initiative, a successful insecticide-based vector control campaign launched in 1991, targeting this particular species. ${ }^{3,4}$ However, because of its inability to form large colonies inside human habitations, and overall low levels of infection with the Trypanosoma cruzi parasite, T. sordida is considered to be of reduced vectorial relevance in both Brazil and Bolivia..$^{1,5,6}$

With respect to T. sordida taxonomy, important genetic differences (allozymic and chromosomal) between populations from Brazil and Argentina, ${ }^{7}$ led to the revalidation of Triatoma garciabesi (formerly T. sordida populations from Argentina), with further support from allozymes and morphology. ${ }^{8}$ In addition, cryptic speciation in T. sordida populations from the Bolivian Chaco was revealed through the detection of diagnostic allozyme loci in sympatric samples. ${ }^{9}$ Factors responsible for these speciation events (i.e., geographic isolation, ecologic segregation) are unknown. Likewise, little is known about which geologic or geographic structures or events might constitute effective gene flow barriers for triatomine populations. ${ }^{10,11}$

Although there are many studies on the application of molecular markers to research Triatominae taxonomic issues, ${ }^{12-17}$ few (with an understandable bias toward T. infestans) are dedicated to most important aspects regarding the planning and execution of vector control initiatives: the assessment of the levels of genetic variation, population structure, and gene flow among insect populations. ${ }^{18-23}$

Thus, this work intends to address two issues: 1) whether there is cryptic speciation in Brazilian populations of $T$. sordida as reported for populations from Argentina and Bolivia; and 2) whether allozymes are suitable molecular markers for the assessment of genetic variability in natural Brazilian T. sordida populations, which would consequently enable population structure inferences.

\footnotetext{
*Address correspondence to Fernando A. Monteiro, Laboratório de Doenças Parasitárias, sala 21A, Instituto Oswaldo Cruz, Fiocruz, Av. Brasil 4365, Rio de Janeiro, RJ, 21045-900, Brazil. E-mail: fam@ioc .fiocruz.br
}

\section{MATERIALS AND METHODS}

Study areas. The four areas studied are located in the central and northern parts of Minas Gerais State, in southeastern Brazil (Figure 1, Table 1), an arid region where the Cerrado, Caatinga, and Parana Forest biogeographic provinces come into contact. ${ }^{24}$ All four sampled areas were poor rural villages where pau-a-pique (wattle and daub) houses were common. This simple building technique is a crucial element in disease transmission as the walls are prone to the formation of cracks and crevices where domestic vectors hide. Subsistence agriculture and rudimentary poultry and livestock breeding (chicken coops and pigsties) were the main human activities observed. Geographic distances between locations ranged from 28 $\mathrm{km}$ (Espinosa and Mamonas) up to $425 \mathrm{~km}$ (Espinosa and Corinto) (Figure 1, Table 2).

Collection of insects. Insects were manually collected from the four sites during a 7-day expedition carried out in December 1996. Areas were selected based on a combination of two factors: 1) long time elapsed since last spraying (over 2 years); and 2) positive reports of triatomine occurrence gathered by the entomologic surveillance centers of each municipality. Ten houses (and peridomestic premises) were sampled from each site. Each house was searched for approximately 30 minutes ( 0.5 person-hour for the inside of houses, and 1 person-hour for the peridomestic premisses).

After collection, triatomines were morphologically identified based on Lent and Wygodzinsky ${ }^{25}$ and stored in liquid nitrogen until genetic analyses.

Allozyme electrophoresis. Horizontal allozyme electrophoresis was carried out using two different support media, to obtain the best resolution possible for the enzyme systems tested: $1 \%$ agarose gels ${ }^{26}$; and cellulose acetate plates. ${ }^{27}$ The head and thorax of each specimen were homogenized in 150 $\mu \mathrm{L}$ of lysis buffer $(0.50 \mathrm{M}$ Tris $\mathrm{HCl}, 0.026 \mathrm{M}$ EDTA, $0.010 \mathrm{M}$ DTT, $0.010 \mathrm{M} \varepsilon$-amino-n caproic acid). The enzyme and buffer systems researched, and the support media used are summarized in Table 3. After electrophoresis, gels were stained according to standard procedures. ${ }^{28}$

Data analysis. Genotype frequencies were obtained by direct genetic interpretation of bands on the gels. From these, gene frequencies, fits to Hardy-Weinberg equilibrium, genetic variation (percentage of polymorphic loci and heterozygosity), inbreeding indices $\left(F_{\mathrm{IS}}, F_{\mathrm{ST}}{ }^{29}\right)$, Contingency Tables, and unbiased genetic distances $\left(D^{30}\right)$ were obtained with the BIOSYS program version $1.7 \cdot{ }^{31}$ The significance of $F_{\mathrm{ST}}\left(\mathrm{H}_{\mathrm{o}}: F_{\mathrm{ST}}=0\right)$ was 


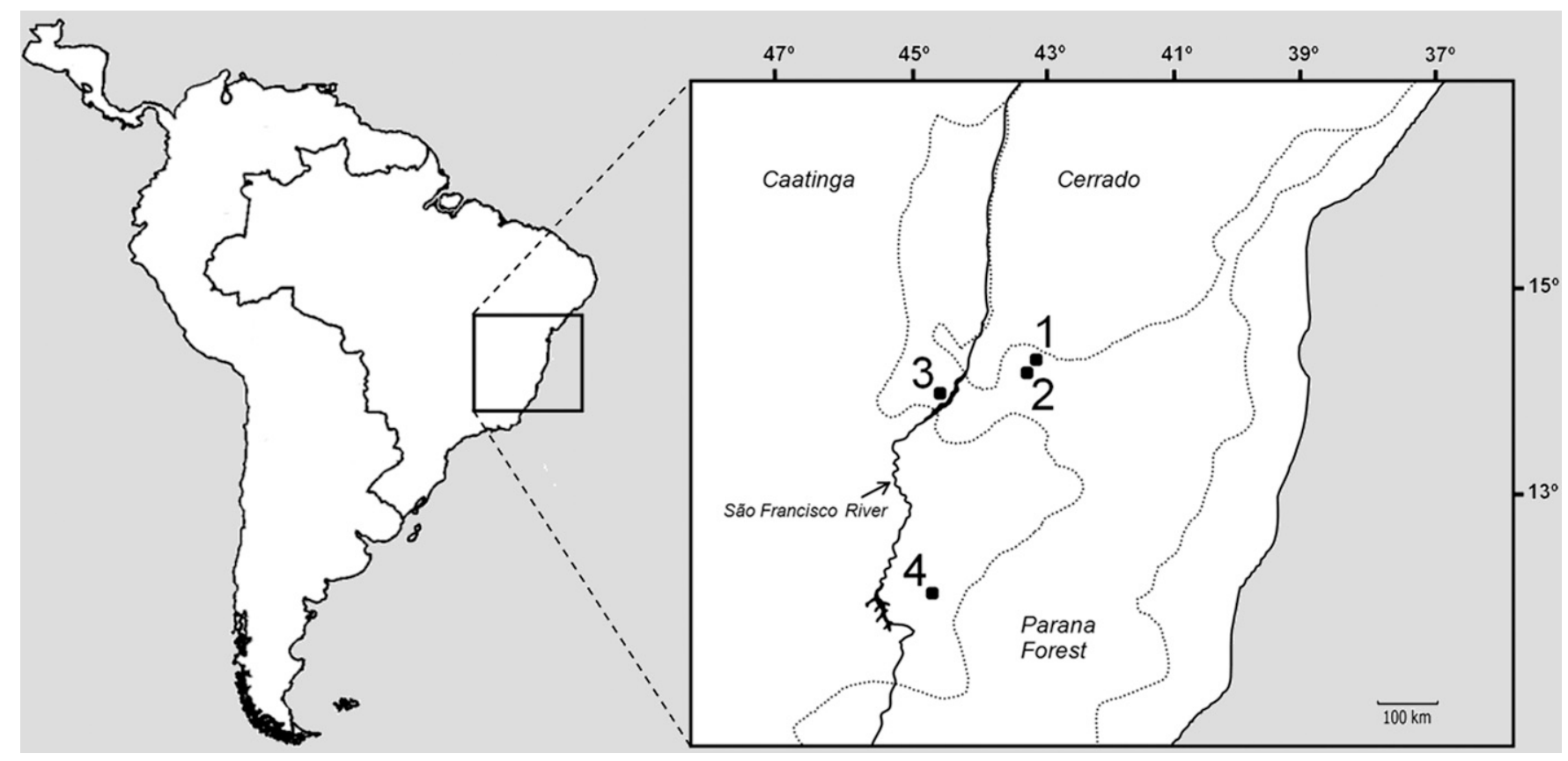

FIGURE 1. Sampling sites of Triatoma sordida populations in Minas Gerais State, southeastern Brazil. (1) Espinosa; (2) Mamonas; (3) Januária; (4) Corinto. Dotted lines represent the boundaries of the Cerrado, Caatinga, and Parana Forest biogeographic provinces. Note that the Januária population is located on the west bank of the wide São Francisco River.

tested according to Waples's $\chi^{2}$ test $^{32}: \chi^{2}=2 N F_{\mathrm{ST}}(k-1) ;$ d.f. $=$ $(k-1)(s-1)$; where $N$ is the total number of individual sampled, $k$ is the number of alleles at the locus, and $s$ is the number of populations.

To research whether geographic distances were directly correlated to genetic distances between pairs of T. sordida populations, we used a Mantel test, with 1,000 replicates, ${ }^{33}$ with the TFPGA program version 1.3. ${ }^{34}$

\section{RESULTS}

Triatoma sordida was the sole species present in the studied area and no insects were found inside human habitations. The majority of insects $(71 \%)$ were captured from chicken coops (or other places used by hens to nest). The remaining insects were captured from wood piles and pigsties. This effort resulted in a total of 181 insects collected from the four geographic populations (see Table 1 for sample sizes per population).

All insects were typed for 28 allozyme loci. The 18 enzyme systems were tested for both electrophoresis support media (Table 3). None of the studied loci presented fixed differences between any pair of populations (i.e., was diagnostic, sensu Ayala $^{35}$ ), and only two loci (Acon-2 and $P g d$ ) revealed polymorphism (Table 4).

As a consequence of the high number of monomorphic loci, values of unbiased genetic distances among populations were

TABLE 1

Sampling sites (with respective geographic coordinates), and sample sizes $(N)$ of the four Triatoma sordida populations studied

\begin{tabular}{lcc}
\hline \multicolumn{1}{c}{ Site } & Coordinates & $N$ \\
\hline (1) Espinosa & $14^{\circ} 55^{\prime} 38^{\prime \prime} \mathrm{S} / 42^{\circ} 48^{\prime} 59^{\prime \prime} \mathrm{W}$ & 68 \\
(2) Mamonas & $15^{\circ} 03^{\prime} 00^{\prime \prime} \mathrm{S} / 42^{\circ} 56^{\prime} 58^{\prime \prime} \mathrm{W}$ & 34 \\
(3) Januária & $15^{\circ} 29^{\prime} 15^{\prime \prime} \mathrm{S} / 44^{\circ} 21^{\prime} 40^{\prime \prime} \mathrm{W}$ & 42 \\
(4) Corinto & $18^{\circ} 21^{\prime} 47^{\prime \prime} \mathrm{S} / 44^{\circ} 27^{\prime} 40^{\prime \prime} \mathrm{W}$ & 37 \\
\hline
\end{tabular}

very low $(D<0.03) .{ }^{30}$ Neither Acon-2 nor Pgd presented significant departures from Hardy-Weinberg expectations in any of the four populations analyzed (exact test: $P>0.05 ; F_{\text {IS }}=0$, $P>0.05$; Table 4). Pairwise $F_{\mathrm{ST}}$ comparisons between populations, as well as Contingency Tables, resulted in significant results (Table 2), indicating the existence of genetic structure.

No significant correlation was observed between geographic distances and genetic differentiation among southeastern Brazilian populations of $T$. sordida (Mantel test: $r=0.774$; $P=0.249)$.

\section{DISCUSSION}

We found no fixed genetic differences (i.e., diagnostic loci) among the studied populations, and very low levels of genetic variability after the analysis of 28 allozyme loci $(P=7.1 \%$; $\left.H_{\mathrm{e}}=0.027\right)$. Regardless of the low levels of polymorphism observed, significant estimates of genetic structure were detected among the four T. sordida populations analyzed from southeast Brazil $\left(F_{\mathrm{ST}}=0.214 ; P<0.05\right)$.

Although hidden taxonomic variation within $T$. sordida from Argentina and Bolivia was disclosed with the use of allozyme markers, ${ }^{7,9}$ we were unable to detect cryptic speciation in the four Brazilian populations studied, even after the analysis of a large number of allozyme loci. The reduced allozyme variability determined in the present work for Brazilian T. sordida populations corroborates earlier reports for other species, ${ }^{18,36-38}$ and indicates what seems to be a rule for Chagas disease vectors.

Low heterozygosity levels were also detected for fieldcollected T. sordida Groups 1 and 2 from the Bolivian Chaco $\left(H_{\mathrm{e}}=0.050\right.$ and 0.065 , respectively ${ }^{9}$, and from colony specimens of the closely related $T$. garciabesi from Argentina $\left(H_{\mathrm{e}}=\right.$ $0.070),{ }^{8}$ and are compatible with the levels found in the present study $\left(H_{\mathrm{e}}=0.027\right)$. On the other hand, García and others ${ }^{39}$ 
TABLE 2

Genetic differentiation $\left(F_{S T}\right)$ and geographic distances (in parentheses*), above diagonal, and $\chi^{2}$ values (Contingency Table $\dagger$ ), below diagonal, among Triatoma sordida populations studied from southeastern Brazil

\begin{tabular}{lccr}
\hline Populations & 1 & 2 & 3 \\
\hline (1) Espinosa & - & $0.007 \ddagger(28)$ & $0.049 \S(179)$ \\
(2) Mamonas & $2.785 \ddagger$ & - & $0.043 \ddagger(156)$ \\
(3) Januária & $17.116 \S$ & $12.893 \S$ & - \\
(4) Corinto & $84.116 \S$ & $50.940 \S$ & $0.184 \S(399)$ \\
\hline
\end{tabular}

$\dagger$ d.f. $=2, P<0.05$, after Bonferroni series. ${ }^{47}$

$\ddagger$ Not significant, $P>0.05$.

$\S P<0.05$, after Bonferroni series

reported a high percentage of polymorphic loci for colony insects of four Triatoma species, with values ranging from $52.9-58.3 \%$. However, if such values are corrected for differences in sample sizes by taking into account the $95 \%$ criterion (i.e., loci for which the frequency of the most common allele exceeds $95 \%$ are considered monomorphic), the percentage of polymorphic loci reported will be considerably reduced (ranging from $7.1 \%$ to $41.7 \%$ ). The T. sordida specimens used in that study were from an F3 colony started with 67 nymphs from Campo Duran, Salta, Argentina, and produced an $H_{\mathrm{e}}$ value of $6.2 \% .^{39}$

The native Panstrongylus megistus (Burmeister 1835) originally abundant in houses of central and eastern Brazil seems to have been progressively displaced by $T$. infestans during the past century. ${ }^{2}$ As $T$. infestans further dispersed northwards, it apparently displaced competitively not only $P$. megistus but T. sordida as well,,$^{40}$ arguably because of its higher efficiency in obtaining bloodmeals. ${ }^{41}$

Triatoma infestans was, until the 1980s, the main domestic vector species present in the studied area (and in the rest of the country for that matter). Vector control campaigns launched in 1991 as part of the Southern Cone Initiative targeting this particular species were very successful, ${ }^{3}$ and by 1995 T. infestans had disappeared from the region. After nationwide successful control achievements, the Brazilian Ministry of Health was awarded the International Elimination of Transmission of Chagas Disease Certificate from the Pan American Health Organization. ${ }^{4}$

As a consequence of the elimination of T. infestans, other secondary vector species such as T. sordida became more fre- quently detected in the studied region. However, Brazilian T. sordida seems only capable of colonizing chicken coops, whereas T. infestans colonizes both chicken coops and houses effectively. For this reason, the nationwide adopted strategy for insecticide application against T. infestans always aimed at both intradomestic and peridomestic structures. This action is likely to have had an impact on the existing sympatric T. sordida peridomestic populations.

Although this study was not originally designed to evaluate the effect insecticide control campaigns against T. infestans had on T. sordida populations, the observation that all four T. sordida peridomestic populations analyzed presented the same two alleles for the same two polymorphic loci seems to favor the interpretation that T. sordida populations were in fact affected by the control actions. Moreover, it suggests that present day peridomestic populations from southeastern Brazil could represent a recent recolonization event derived from a residual peridomestic focus. Otherwise, if T. sordida populations were not affected by control actions, the most likely result would have been the detection of high and randomly distributed variability across examined loci. Nonetheless, as T. sordida is autochthonous in Brazil, it is worthwhile to speculate on the role that natural sylvatic populations (supposedly unaffected by the control actions) would have played in the recolonization of treated areas. Given the low levels of genetic variation observed, it seems unlikely that sylvatic $T$. sordida populations would have served as genetic diversity reservoirs during insecticide control efforts (assuming that sylvatic populations are genetically more variable than peridomestic populations).

TABLE 3

Enzyme systems (with respective number of scored loci) and support media used in this study*

\begin{tabular}{|c|c|c|c|c|}
\hline Enzyme & Enzyme code (EC) no. & Abbreviation & Medium & No. of loci \\
\hline Aconitase & 4.2.1.3 & $\mathrm{ACON}$ & Agarose & 2 \\
\hline Diaphorase & 1.6.2.2 & DIA & Acetate & 1 \\
\hline$\alpha$-Esterases & 3.1.1.1 & $\alpha$-EST & Agarose & 2 \\
\hline Glucose-6-phosphate dehydrogenase & 1.1.1.49 & G6PDH & Agarose & 2 \\
\hline Glucose-6-phosphate isomerase & 5.3.1.9 & PGI & Agarose & 1 \\
\hline Glutamate dehydrogenase & 1.4.1.4 & GDH & Agarose & 1 \\
\hline Glutamate oxaloacetate transaminase & 2.6.1.1 & GOT & Acetate & 1 \\
\hline$\alpha$-Glycerophosphate dehydrogenase & 1.1.1.8 & $\alpha-G P D$ & Agarose & 2 \\
\hline Hexokinase & 2.7.1.1 & HK & Acetate & 2 \\
\hline Isocitrate dehydrogenase & 1.1.1.42 & IDH & Agarose & 1 \\
\hline Leucine aminopeptidase & 3.4.11.1 & LAP & Acetate & 2 \\
\hline Malate dehydrogenase & 1.1.1.37 & $\mathrm{MDH}$ & Acetate & 2 \\
\hline Mannose 6-phosphate isomerase & 5.3.1.8 & MPI & Agarose & 1 \\
\hline Malic enzyme & 1.1.1.40 & ME & Acetate & 1 \\
\hline Peptidases (pro-phe) & 3.4.1.1 & PEP & Acetate & 3 \\
\hline Phosphogluconate mutase & 5.4.2.2 & PGM & Agarose & 1 \\
\hline Phosphogluconate dehydrogenase & 1.1.1.44 & PGD & Acetate & 1 \\
\hline Superoxide dismutase & 1.15.1.1 & SOD & Acetate & 2 \\
\hline
\end{tabular}

*The Tris-citrate $\mathrm{pH} 8.0$ (0.25 M Tris, $0.06 \mathrm{M}$ citrate, $\mathrm{pH} 8.0)^{48}$ buffer system was used with both electrophoresis support media. 
TABLE 4

Gene frequencies and fits to Hardy-Weinberg expectations $\left(F_{\text {IS }}\right)$, for the two polymorphic loci for four Triatoma sordida peridomestic populations from southeastern Brazil, and observed $\left(H_{\mathrm{o}}\right)$ and expected $\left(H_{\mathrm{e}}\right)$ mean heterozygosities for all 28 loci studied*

\begin{tabular}{|c|c|c|c|c|c|}
\hline \multirow[b]{2}{*}{ Locus } & \multirow[b]{2}{*}{ Allele } & \multicolumn{4}{|c|}{ Population } \\
\hline & & Espinosa & Mamonas & Januária & Corinto \\
\hline \multirow[t]{4}{*}{ Acon-2 } & 1 & 0.546 & 0.574 & 0.821 & 0.162 \\
\hline & 2 & 0.454 & 0.426 & 0.179 & 0.838 \\
\hline & $(N)$ & $(65)$ & (34) & $(42)$ & (37) \\
\hline & $F_{\text {IS }}$ & $0.108+$ & $0.352 \dagger$ & $0.281 \dagger$ & $0.217 \dagger$ \\
\hline \multirow[t]{4}{*}{$P g d$} & $1^{1 \mathrm{IS}}$ & 0.221 & 0.328 & 0.230 & 0.757 \\
\hline & 2 & 0.779 & 0.672 & 0.770 & 0.243 \\
\hline & $(N)$ & (68) & (32) & $(37)$ & $(35)$ \\
\hline & $F_{\text {IS }}$ & $0.237 \dagger$ & $0.235 \dagger$ & $0.325 \dagger$ & $0.160 \dagger$ \\
\hline$H_{\mathrm{o}}$ & & 0.025 & 0.024 & 0.016 & 0.019 \\
\hline$H_{\mathrm{e}}^{\mathrm{o}}$ & & 0.030 & 0.034 & 0.023 & 0.023 \\
\hline
\end{tabular}

Population structure inferences, although preliminary because of the small number of polymorphic loci detected, revealed significant results for most pairwise comparisons made, indicating the existence of genetic differentiation. A Mantel test used to assess whether populations exhibited a pattern compatible with the isolation by distance model (IBD), was statistically non-significant ( $r=0.774 ; P=0.249$ ), in contrast to findings for T. sordida Group 1 populations from Bolivia that were compatible with the IBD model. ${ }^{19}$ Unfortunately, no data was ever generated for either T. sordida Group 2, or T. garciabesi to allow their testing for IBD.

Alternative hypotheses to explain the pattern of genetic structure found should take into account the possible influence current geographic barriers might have on the restriction of gene flow between the studied populations. Januária is the sole population located west of the São Francisco River (Figure 1), which presently has an estimated $730 \mathrm{~m}$ in breadth. Interestingly, what became evident from the genetic structure estimates, was that Januária and Corinto populations are more differentiated $\left(F_{\mathrm{ST}}=0.356\right)$ than, for example, the geographically most distant sites compared (Mamonas versus Corinto: $F_{\mathrm{ST}}=0.184$; Espinosa versus Corinto: $\left.F_{\mathrm{ST}}=0.227\right)$. Although it is possible that large rivers could act as barriers to gene flow for triatomines, this hypothesis has not been addressed using appropriate sampling designs. ${ }^{11}$

Population level studies require information on a large number of polymorphic loci to allow for the formulation of robust population structure inferences, and the very low levels of variation here reported represent a clear limitation in that regard. Microsatellite markers, which have already been isolated and characterized for five triatomine species,${ }^{4-46}$ present advantages over the traditional allozymes, because of their faster evolution rate (and thus expected higher variability), and the non-requirement of fresh (or frozen) samples for the laboratory procedures. Therefore, they will most likely replace the traditional allozymes as the markers of choice for triatomine population level investigations in the near future. The development of microsatellite loci for T. sordida will enable the testing of the allozyme-based genetic structure here detected.

It would be important for the better understanding of the taxonomy of this species complex to determine the phylogenetic relationship that the T. sordida samples studied here have with respect to the cryptic species detected in Argentina and Bolivia. This would enable the characterization and subse- quent identification of the epidemiologically relevant targets to be combated in each country.

Received December 30, 2008. Accepted for publication March 12, 2009.

Acknowledgments: We thank João F. Martins for technical assistance, and the personnel of the National Health Foundation in Brazil (FUNASA), for help during the field collections. Haydée Cunha and an anonymous referee made insightful comments that improved the manuscript. Agarose allozyme electrophoresis was carried out in the laboratory of Ricardo Lourenço-de-Oliveira.

Financial support: This work was supported by the Brazilian National Research Council, CNPq.

Authors' addresses: Fernando A. Monteiro, Laboratório de Doenças Parasitárias, sala 21A, Instituto Oswaldo Cruz, Fiocruz, Av. Brasil 4365, Rio de Janeiro, RJ, 21045-900, Brazil, Tel: +55 21 2562-1255, Fax: +55 21 2280-3470, E-mail: fam@ioc.fiocruz.br. José Jurberg, Laboratório Nacional e Internacional de Referência em Taxonomia de Triatomíneos, Instituto Oswaldo Cruz, Fiocruz, Rio de Janeiro, Brazil, Tel: +55 21 2598-4518, Fax: +55 21 2560-7317, E-mail: jjurberg @ioc.fiocruz.br. Cristiano Lazoski, Laboratório de Biodiversidade Molecular, Departamento de Genética, Universidade Federal do Rio de Janeiro, CCS, Bloco A, sala A2-98, Ilha do Fundão, Rio de Janeiro, RJ, 21941-590, Brazil, Tel: +55 21 2562-6389, Fax: +55 21 2562-6333, E-mail: lazoski@acd.ufrj.br.

\section{REFERENCES}

1. Diotaiuti L, Pereira AS, Loiola CF, Fernandes AJ, Schofield JC, Dujardin JP, Dias JC, Chiari E, 1995. Inter-relation of sylvatic and domestic transmission of Trypanosoma cruzi in areas with and without domestic vectorial transmission in Minas Gerais, Brazil. Mem Inst Oswaldo Cruz 90: 443-448.

2. Pereira MH, Gontijo NF, Guarneri AA, Sant'Anna MR, Diotaiuti L, 2006. Competitive displacement in Triatominae: the Triatoma infestans success. Trends Parasitol 22: 516-520.

3. Schofield CJ, Dias JC, 1999. The Southern Cone Initiative against Chagas disease. Adv Parasitol 42: 1-27.

4. PAHO, 2006. The Newsletter of the Pan American Health Organization. Available at: http://www.paho.org/English/DD/ PIN/ptoday24_aug06.htm. Accessed December 12, 2008.

5. Noireau F, Flores R, Gutierrez T, Dujardin JP, 1997. Detection of sylvatic dark morphs of Triatoma infestans in the Bolivian Chaco. Mem Inst Oswaldo Cruz 92: 583-584.

6. Herrera L, Pinho AP, Lorosa E, Xavier SCC, Emperaire L, Mangia RH, 2003. Studies of triatomine infection with Trypanosoma cruzi in João Costa, Piauí, Brazil. Acta Parasitol 48: 1230-2821.

7. Panzera F, Hornos S, Pereira J, Cestau R, Canale D, Diotaiuti L, Dujardin JP, Pérez R, 1997. Genetic variability and geographic differentiation among three species of triatomine bugs (Hemiptera: Reduviidae). Am J Trop Med Hyg 57: 732-739.

8. Jurberg J, Galvao C, Lent H, Monteiro FA, Lopes CM, Panzera F, Perez R, 1998. Revalidação de Triatoma garciabesi Carcavallo, Martinez, Cichero, Prosen \& Ronderos, 1967 (Hemiptera: Reduviidae). Entomol Vect 5: 107-122.

9. Noireau F, Gutierrez T, Zegarra M, Flores R, Breniere F, Cardozo L, Dujardin JP, 1998. Cryptic speciation in Triatoma sordida (Hemiptera: Reduviidae) from the Bolivian Chaco. Trop Med Int Health 3: 364-372.

10. Abad-Franch F, Monteiro FA, 2007. Biogeography and evolution of Amazonian triatomines (Heteroptera: Reduviidae): implications for Chagas disease surveillance in humid forest ecoregions. Mem Inst Oswaldo Cruz 102: 57-70.

11. Conn JE, Mirabello L, 2007. The biogeography and population genetics of neotropical vector species. Heredity 99: 245-256.

12. Dujardin JP, Tibayrenc M, Venegas E, Maldonado L, Desjeux P, Ayala FJ, 1987. Isoenzyme evidence of lack of speciation between wild and domestic Triatoma infestans (Heteroptera: Reduviidae) in Bolivia. J Med Entomol 24: 40-45.

13. Harry M, 1993. Isozymic data question the specific status of some blood-sucking bugs of the genus Rhodnius, vectors of Chagas disease. Trans R Soc Trop Med Hyg 87: 492-493. 
14. Monteiro FA, Pérez R, Panzera F, Dujardin JP, Galvão C, Rocha D, Noireau F, Schofield C, Beard CB, 1999. Mitochondrial DNA variation of Triatoma infestans populations and its implication on the specific status of T. melanosoma. Mem Inst Oswaldo Cruz 94: 229-238.

15. Monteiro FA, Barrett TV, Fitzpatrick S, Cordon-Rosales C, Feliciangeli D, Beard CB, 2003. Molecular phylogeography of the Amazonian Chagas disease vectors Rhodnius prolixus and R. robustus. Mol Ecol 12: 997-1006.

16. Monteiro FA, Donnelly MJ, Beard CB, Costa J, 2004. Nested clade and phylogeographic analyses of the Chagas disease vector Triatoma brasiliensis in Northeast Brazil. Mol Phylogenet Evol 32: 46-56.

17. Bargues MD, Klisiowicz DR, Gonzalez-Candelas F, Ramsey JM, Monroy C, Ponce C, Salazar-Schettino PM, Panzera F, AbadFranch F, Sousa OE, Schofield CJ, Dujardin JP, Guhl F, MasComa S, 2008. Phylogeography and genetic variation of Triatoma dimidiata, the main Chagas disease vector in Central America, and its position within the genus Triatoma. PLoS Negl Trop Dis 2: e233.

18. Dujardin JP, Schofield CJ, Tibayrenc M, 1998. Population structure of Andean Triatoma infestans: allozyme frequencies and their epidemiological relevance. Med Vet Entomol 12: 20-29.

19. Noireau F, Zegarra M, Ordoñez J, Gutierrez T, Dujardin JP, 1999. Genetic structure of Triatoma sordida (Hemiptera: Reduviidae) domestic populations from Bolivia: application on control interventions. Mem Inst Oswaldo Cruz 94: 347-351.

20. Pérez de Rosas AR, Segura EL, García BA, 2007. Microsatellite analysis of genetic structure in natural Triatoma infestans (Hemiptera: Reduviidae) populations from Argentina: its implication in assessing the effectiveness of Chagas disease vector control programmes. Mol Ecol 16: 1401-1412.

21. Fitzpatrick S, Feliciangeli MD, Sanchez-Martin MJ, Monteiro FA, Miles MA, 2008. Molecular genetics reveal that silvatic Rhodnius prolixus do colonise rural houses. PLoS Negl Trop Dis 2: 997-1006.

22. Marcet PL, Mora MS, Cutrera AP, Jones L, Gürtler RE, Kitron U, Dotson EM, 2008. Genetic structure of Triatoma infestans populations in rural communities of Santiago del Estero, northern Argentina. Infect Genet Evol 8: 835-846.

23. Pizarro JC, Gilligan LM, Stevens L, 2008. Microsatellites reveal a high population structure in Triatoma infestans from Chuquisaca, Bolivia. PLoS Negl Trop Dis 2: 1-8.

24. Morrone JJ, 2006. Biogeographic areas and transition zones of Latin America and the Caribbean islands based on panbiogeographic and cladistic analyses of the entomofauna. Annu Rev Entomol 51: 467-494.

25. Lent H, Wygodzinsky P, 1979. Revision of the Triatominae (Hemiptera: Reduviidae) and their significance as vectors of Chagas disease. Bull Am Mus Nat Hist 163: 123-520.

26. Momen H, Salles CA, 1985. Enzyme markers for Vibrio cholerae: identification of classical, eltor and environmental strains. Trans $R$ Soc Trop Med Hyg 79: 773-776.

27. Dujardin JP, Tibayrenc M, 1985. Study of 11 enzymes and formal genetic findings for 19 enzymatic loci in Triatoma infestans (Hemiptera: Reduviidae). Ann Soc Belg Med Trop 65: 271-280.

28. Manchenko GP, 1994. Handbook of Detection of Enzymes on Electrophoretic Gels. Michigan: CRC Press Inc.

29. Wright S, 1978. Evolution and the Genetics of Populations. Volume 4. London: The University of Chicago Press.

30. Nei M, 1978. Estimation of average heterozygosity and genetic distance from a small number of individuals. Genetics 89: $583-590$.
31. Swofford DL, Selander RB, 1981. BIOSYS-1, a FORTRAN programme for the comprehensive analysis of electrophoretic data in population genetics and systematics. $J$ Hered 72: 281-283.

32. Waples RS, 1987. A multispecies approach to the analysis of gene flow in marine store fishes. Evolution Int J Org Evolution 41 : 385-400.

33. Sokal RR, Rohlf FJ, 1995. Biometry: The Principles and Practice of Statistics in Biological Research. San Francisco, CA: Freeman $\mathrm{WH}$ and $\mathrm{Co}$.

34. Miller MP, 1997. Tools for population genetic analyses (TFPGA) version 1.3: a Windows program for the analysis of allozyme and molecular population genetic data. Programme distributed by the author

35. Ayala FJ, 1983. Enzymes as taxonomic characters. Oxford GS Rollinson D, eds. Protein Polymorphism: Adaptive and Taxonomic Significance. London: Academic Press, 3-26.

36. Borges EC, Dujardin JP, Schofield CJ, Romanha AJ, Diotaiuti L, 2000. Genetic variability of Triatoma brasiliensis (Hemiptera: Reduviidae) populations. J Med Entomol 37: 872-877.

37. Monteiro FA, Lazoski C, Noireau F, Sole-Cava AM, 2002. Allozyme relationships among ten species of Rhodniini, showing paraphyly of Rhodnius including Psammolestes. Med Vet Entomol 16: 83-90.

38. dos Santos SM, Lopes CM, Dujardin JP, Panzera F, Pérez R, Carbajal de la Fuente AL, Pacheco RS, Noireau F, 2007. Evolutionary relationships based on genetic and phenetic characters between Triatoma maculata, T. pseudomaculata and morphologically related species (Reduviidae: Triatominae). Infect Genet Evol 7: 469-475.

39. García BA, Canale DM, Blanco A, 1995. Genetic structure of four species of Triatoma (Hemiptera: Reduviidae) from Argentina. J Med Entomol 32: 134-137.

40. Schofield CJ, 1980. Density regulation of domestic populations of Triatoma infestans in Brazil. Trans $R$ Soc Trop Med Hyg 74: 761-769.

41. Oscherov EB, Damborsky MP, Bar ME, Gorla DE, 2004. Competition between vectors of Chagas disease, Triatoma infestans and T. sordida: effects on fecundity and mortality. Med Vet Entomol 18: 323-328.

42. Harry M, Poyet G, Romaña CA, Solignac M, 1998. Isolation and characterization of microsatellite markers in the bloodsucking bug Rhodnius pallescens (Heteroptera, Reduviidae). Mol Ecol 7: $1784-1786$.

43. Harry M, Dupont L, Romana C, Demanche C, Mercier A, Livet A, Diotaiuti L, Noireau F, Emperaire L, 2008. Microsatellite markers in Triatoma pseudomaculata (Hemiptera, Reduviidae, Triatominae), Chagas disease vector in Brazil. Infect Genet Evol 8: 672-675.

44. Harry M, Roose CL, Vautrin D, Noireau F, Romaña CA, Solignac M, 2008. Microsatellite markers from the Chagas disease vector, Rhodnius prolixus (Hemiptera, Reduviidae), and their applicability to Rhodnius species. Infect Genet Evol 8: 381-385.

45. Anderson JM, Lai JE, Dotson EM, Cordon-Rosales C, Ponce C, Norris DE, Beard CB, 2002. Identification and characterization of microsatellite markers in the Chagas disease vector Triatoma dimidiata. Infect Genet Evol 1: 243-248.

46. Marcet PL, Lehmann T, Groner G, Gürtler RE, Kitron U, Dotson EM, 2006. Identification and characterization of microsatellite markers in the Chagas disease vector Triatoma infestans (Heteroptera: Reduviidae). Infect Genet Evol 6: 32-37.

47. Lessios HA, 1992. Testing electrophoretic data for agreement with Hardy-Weinberg expectations. Mar Biol 112: 517-523.

48. Ward RD, Beardmore JA, 1977. Protein variation in the plaice (Pleuronectes platessa). Genet Res 30: 45-62. 